\title{
55
}

\section{Sensory Setae of the First Tarsi and Palps of the Mite Macrocheles muscaedomesticae ${ }^{1,2}$}

\author{
L. B. COONS AND R. C. AXTELL \\ Department of Entomology, North Carolina State University, Raleigh 27607
}

\begin{abstract}
By scanning and transmission electron microscopy, blunt-peg type of sensilla (sensilla basiconica) were found on the tarsus of the 1st leg of Macrocheles muscaedomesticae (Scopoli). The changes in number, size, and position were determined for each life stage. The num-

ber of blunt pegs in the larva, protonymph, deutonymph, and adult stages were $6,7,8$, and 8 , respectively. Similar sensilla were not found on the terminal segment of the palps.
\end{abstract}

Marcrocheles muscaedomestica (Scopoli) is a manure-inhabiting mesostigmatid mite of considerable interest as a predator on eggs and 1st-stage larvae of muscoid flies (Axtell 1969 and references therein). Use of this and other macrochelid species as biological control agents has been proposed (Filipponi 1964). Integrated fly control programs in caged-poultry houses (Anderson and Poorbaugh 1964; Axtell 1968, 1970a,b; Peck and Anderson 1969a,b, 1970) have incorporated measures to maximize the abundance of these and other predaceous manure-inhabiting mites (as well as parasites).

Its importance as a predator and ease of rearing (Wade and Rodriguez 1961) have encouraged use of $M$. muscaedomesticae in basic investigations as a representative of free-living mesostigmatid mites (Coons and Axtell 1971a, b). Particular attention has been devoted to elucidation of the sensory behavior in relation to predation and phoresy (Farish and Axtell 1966, 1971; Jalil and Rodriguez 1970). Based on amputation and behaviorial experiments, the 1st tarsi were shown to be involved in the reception of olfactory stimuli, and receptors of contact stimuli to be situated on the palps. Therefore, we examined the distal portion of the 1st tarsi and palps by scanning and transmission electron microscopy, as well as light microscopy, in an attempt to locate the sensory receptors in the various developmental stages (larva, protonymph, deutonymph, and adult).

\section{MATERIALS AND METHODS}

For light microscopy (phase-contrast), the 1st pair of legs and palps of all life stages were slide-mounted in Hoyer's or PVA medium with and without prior clearing in $10 \% \mathrm{KOH}$. Some specimens were stained according to the method of Osorno-Mesa et al. (1966). Drawings were made with the aid of a drawing tube.

Material to be examined with the JSM-2 scanning electron microscope was prepared in several ways. Mites were fixed in $25 \%$ gluteraldehyde, $80 \%$ ethyl alcohol, or $100 \%$ acetone. The fixative containing gluteraldehyde was buffered identical to that used in

${ }^{1}$ Acarina: Mesostigmata: Macrochelidae.

2 This research was supported in part by the Office of Naval Research Naval Biology Program, under contract no N00014-70. A-0120-0001, NR 306-033 and Training Grant ES00069 from the National Institutes of Environmental Health Sciences. Paper no. 3876 of the Journal Series of the North Carolina State University A rricultural Experiment Station. Received for publication Sept. 29,1972 . preparing tissue for the transmission electron microscope. After fixing the mites in gluteraldehyde for 12-24 hr at $6^{\circ} \mathrm{C}$, the specimens were stored in icecold $0.05 \mathrm{M}$ sodium cacodylate buffer. Mites were placed on bibulous paper to absorb moisture, then mounted with double-faced cellophane tape on scanning electron microscope specimen stubs. These were coated with gold palladium in a vacuum evaporator. Some live specimens were coated with the same material.

For transmission electron microscopy, the tarsal segment of leg I and the entire palps were severed from live mites and immediately immersed in ice-cold fixative consisting of $2.5 \%$ gluteraldehyde buffered with $0.05 \mathrm{M}$ sodium cacodylate $(\mathrm{pH} 7.2)$ containing $0.15 \mathrm{M}$ sucrose. The tissue was washed for several hours in the cacodylate buffer containing sucrose, and then postfixed in $1 \%$ osmium tetroxide in veronal acetate buffer ( $\mathrm{pH} 7.2$ ) containing $0.30 \mathrm{M}$ sucrose. After dehydration in a graded series of concentrations of ethyl alcohol and several changes of propylene oxide, the tissue was infiltrated and embedded in Epon 812 according to the method of Luft (1961). All steps in this procedure prior to dehydration in absolute alcohol were at $2-6^{\circ} \mathrm{C}$.

Tissue blocks were sectioned with a diamond knife using either a Reichert OM U2, or MT-1 Sorvall "Porter-Blum" ultramicrotome. Sections were picked up on formvar-coated copper grids and double stained in saturated uranyl acetate in 50\% ethyl alcohol (10 min) and lead citrate $(8 \mathrm{~min})$ (Venable and Coggeshall 1965). "Drifting" of sections in the electron beam was prevented by evaporating a thin layer of carbon on them in a vacuum-evaporating device. Sections were examined with either a Siemans Elmskop II at $50 \mathrm{kV}$ or a Siemans Elmskop I-A at $80 \mathrm{kV}$.

\section{RESULTS}

First Tarsi.-A group of pointed setae and blunt pegs was found on the end of the 1st tarsi of each stage of the life cycle. These short blunt pegs have an external morphology characteristic of the sensilla basiconica of insects (Slifer 1970). The number, size, and position of these blunt pegs change during postembryonic development. The larval pattern is the simplest and consists of 6 blunt pegs (Fig. 1). The pegs are arranged on one side of the end of the 1st tarsi in 2 areas. A group of 4 pegs is found at the 

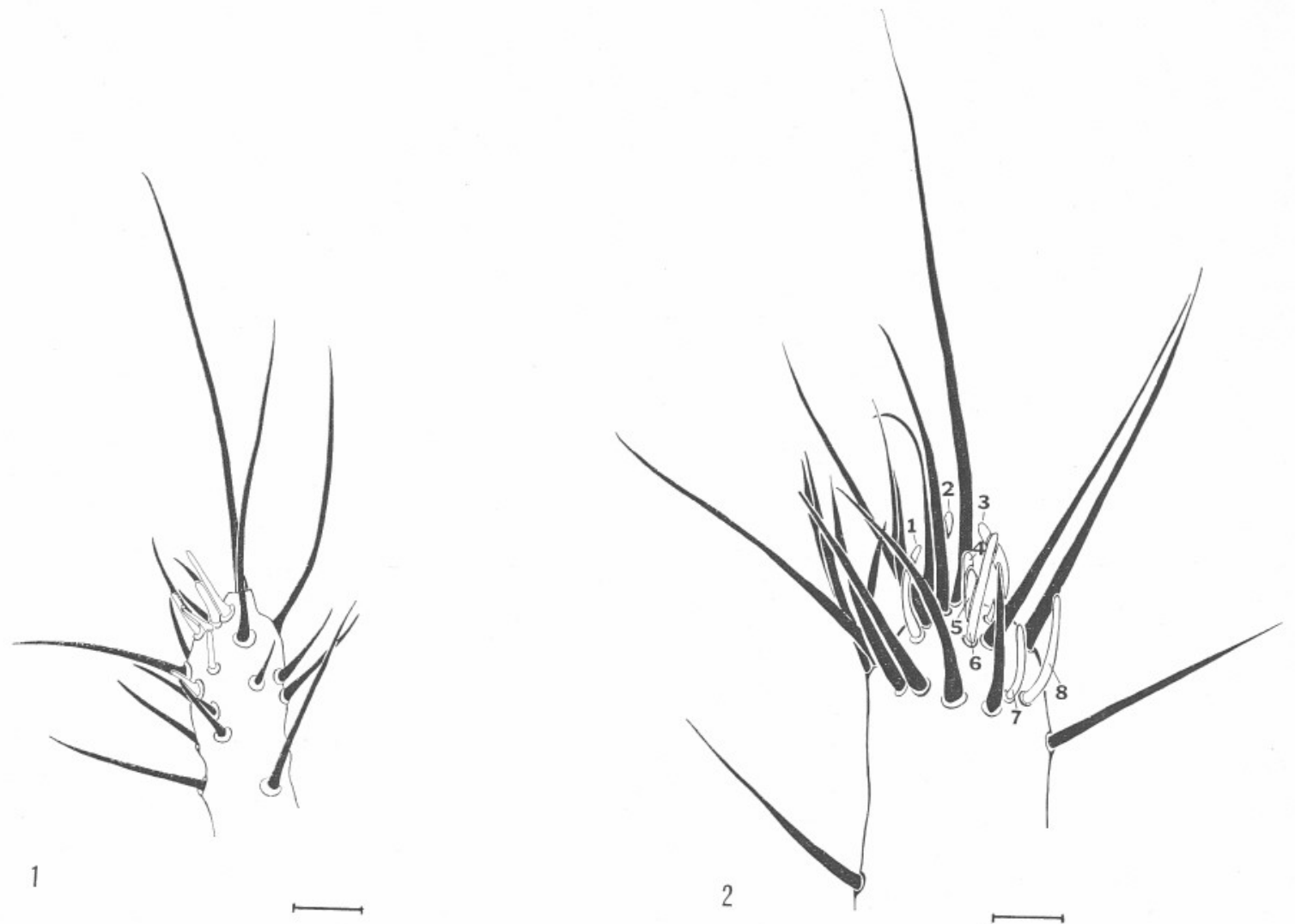

FIG. 1-2.-Drawing of the setal arrangement on the end of tarsi I of $M$. muscaedomesticae. Blunt pegs are shown in outline (and numbered in Fig. 2); other setae are blackened. Line marker equals 10 $\mu$. 1, Larva; 2 , adult female.

very distal end of tarsi I and proximally, a 2nd group of 2 pegs.

The protonymph has 7 blunt pegs, while the deutonymph and adult have 8 blunt pegs (Fig. 2). In these stages the blunt pegs are found in 2 areas at the tip of tarsi I. In one area (terminal) there are 3 curved blunt pegs (no. 1-3, Fig. 2) and 3 straight blunt pegs (no. 4-6, Fig. 2) surrounded by long pointed setae. The number and external appearance of the pegs in this area do not change from protonymph to adult, although their general size increases with increase in size of the specific life cycle stage. The other area (more proximal and lateral) has 1 curved blunt peg in the protonymph and 2 (no. 7 \& 8, Fig. 2) in the deutonymph and adult.

Scanning electron microscopy of the 1st tarsi of the adult female mites showed the presence of many small papillae on the surface of some of the blunt pegs when the specimens were fixed in $80 \%$ ethyl alcohol or $100 \%$ acetone (Fig. 3, 4). In alcohol-fixed material, papillae had a more uniform appearance with a conical head and a constricted base. Papillae were not present on any of the blunt pegs from material fixed in gluteraldehyde or on blunt pegs from unfixed material (Fig. 5). These surface papillae were artifacts; probably material extruded from the interior of the pegs through action of the alcohol and acetone. These artifacts are emphasized because: (1) they helped in detecting the presence of blunt pegs and might be profitably used in examinations of other organisms, and (2) this example illustrates the caution necessary in describing structures based on scanning electron microscopy.

Two types of innervated setae were found: porous and nonporous. The porous types had a cuticular wall with a central cavity (Fig. 6, 7). This cavity was confluent, in at least some areas, with the many pores. Perhaps the surface papillae were formed by extrusion of material through these pores but that hypothesis was not proved. The central lumen of the porous setae contained dendrites. The pore diameters were about $0.013 \mu$ (Fig. 6), and about $0.026 \mu$ (Fig. 7). Nonporous setae also had a cuticular wall with a central cavity. A cuticular sheath and dendrites were found within the cavity (Fig. 8, 9). It is likely that these setae have a single opening at or near the tip.

Palp.- No blunt pegs, similar to those on the 1st tarsi, were found on the palpal tarsi. Postembryonic changes of the setae on the palpal tarsi occur. The most noticeable difference occurs during the 1st molt between the larva and protonymph. Besides addition of more long pointed setae, the one small thick 

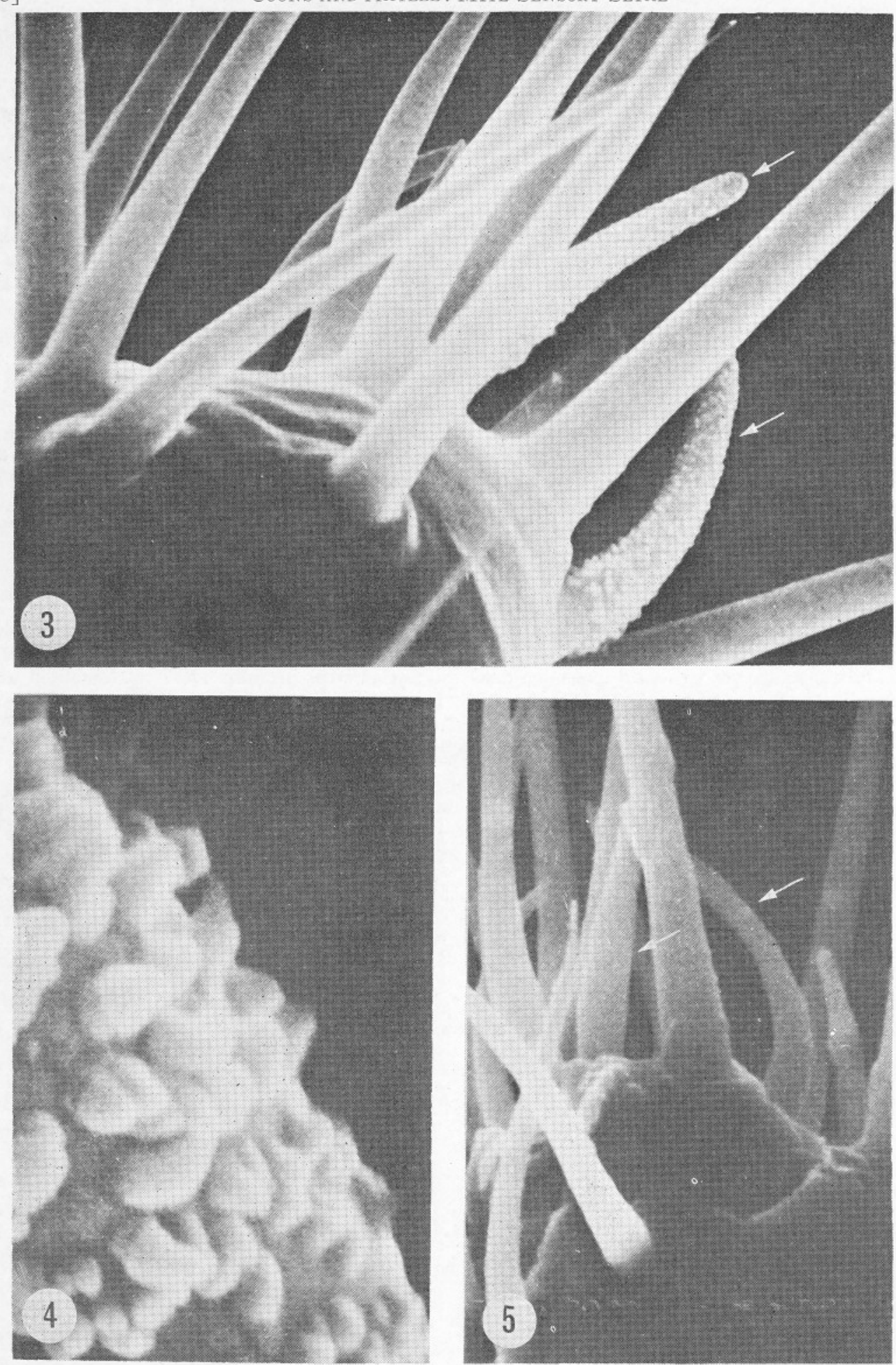

FIG. 3.-Scanning electron micrograph of the setae on the end of tarsi I of an adult female mite. Many small papillae appear on the surface of 2 of the curved blunt pegs (arrows). Material was fixed in $80 \%$ ethyl alcohol. Note that the papillae are absent from surrounding setae and from at least one curved peg. $\times 3500$.

FIG, 4.-High magnification scanning electron micrograph of the papillae on one of the curved blunt pegs seen at a lower magnification in Fig. 3. These papillae appear to have a conical head and a constricted base. Material fixed in $80 \%$ ethyl alcohol. $\times 60,000$.

FIG. 5.- Scanning electron micrograph of the setae at the end of tarsi I of an adult female mite. Note the absence of papillae on the curved blunt pegs (arrows). Unfixed material, killed during coating for scanning electron microscopy. $\times 3600$ 
seta becomes about 6 times longer in the protonymph than in the larva. During the remaining postembryonic development, the general arrangement of the setae found in the protonymph is retained. The principal change is an increase in the size of the life stages following the 2 nd and 3rd molts.

Scanning electron microscope of the end of the palps confirmed the observations made with the light microscope that blunt pegs were absent from this region (Fig. 10). Incidental to this study was the observation that the "tined seta" or "palpal apotele" is set within a depression. With scanning electron microscopy, the tines of the palpal apotele appeared to have pronounced blunt endings, while specimens viewed with the light microscope appeared to have pointed tines.

Transmission electron microscopy of the end of the palps did not show the presence of any porous sensilla but only a few sections were obtained. Sections through the palpal apotele failed to show any innervation of this structure. As in other mesostigmatid mites (Camin et al. 1958), it has a muscle that inserts at its base, suggesting the capability for movement.

\section{DISCUSSION}

Blunt-peg-type sensilla are generally considered to have an olfactory function (Slifer 1970) although in- frared radiation reception has been proposed (Bruce 1971). Their presence on the tip of the 1st tarsi and absence on the palps correlates with the previous evidence of an olfactory function for the former and nonolfactory function for the latter (Farish and Axtell 1966). The porous type of setae found in cross sections of the 1st tarsi (Fig. 7) probably correspond to the blunt-tip setae observed by scanning electron microscopy. In cross-section they resemble closely the medial (= 4-group) setae proximal to Haller's organ in the hard tick Amblyomma americanum (L.) (Foelix and Axtell 1971, 1972; Axtell et al. 1973). The different type of porous setae shown in Fig. 6 suggests there are 2 types of blunt pegs. Perhaps this feature corresponds to the curved and straight types observed by light microscopy.

The nonporous setae probably correspond to the long-pointed setae on the tarsus. The presence of a lumen, dendrites in the shaft, and gross shape suggests sensory function. It is reasonable to assume that they have a tactile function, but no evidence was found of a tubular body at the base, which is generally accepted as evidence of a mechanoreceptor. The presence of dendrites in the shaft suggests there might be an opening at or near the tip for reception of contact stimuli, but such an opening was not demonstrated.

Serial cross sections were not obtained and therefore it is not possible to specifically attribute Fig. 6-9
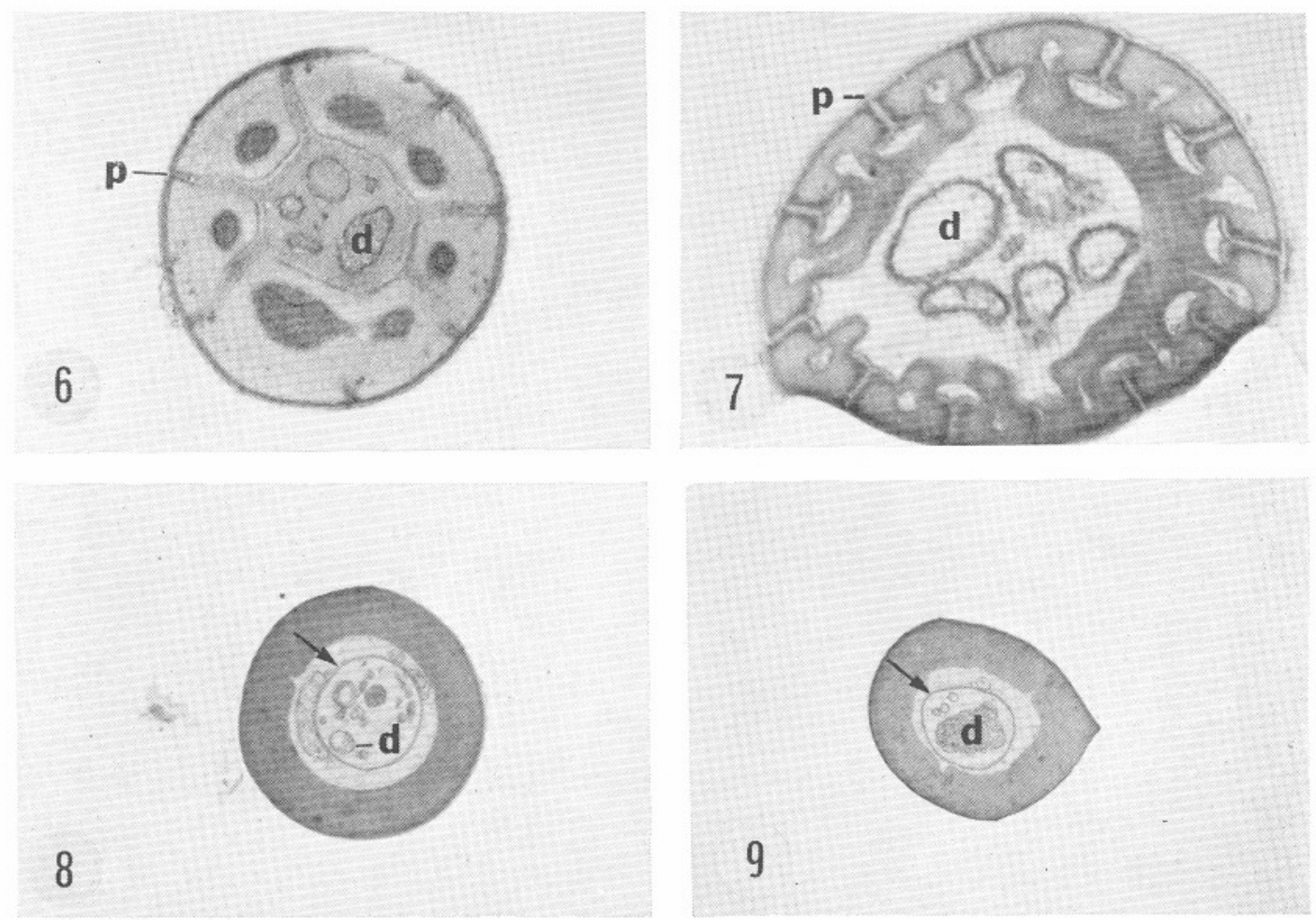

FIG. 6-7.-Transmission electron micrographs of 2 porous pegs on the end of tarsi I of an adult female mite. The porous openings (p) and the dendrites (d) are identified. $\times 30,000$.

FIG. 8-9.-Transmission electron micrographs of 2 nonporous pegs on the end of tarsi I of an adult female mite. Dendrites (d), and what is probably a cuticular sheath (arrows) are identified. $\times 30,000$. 


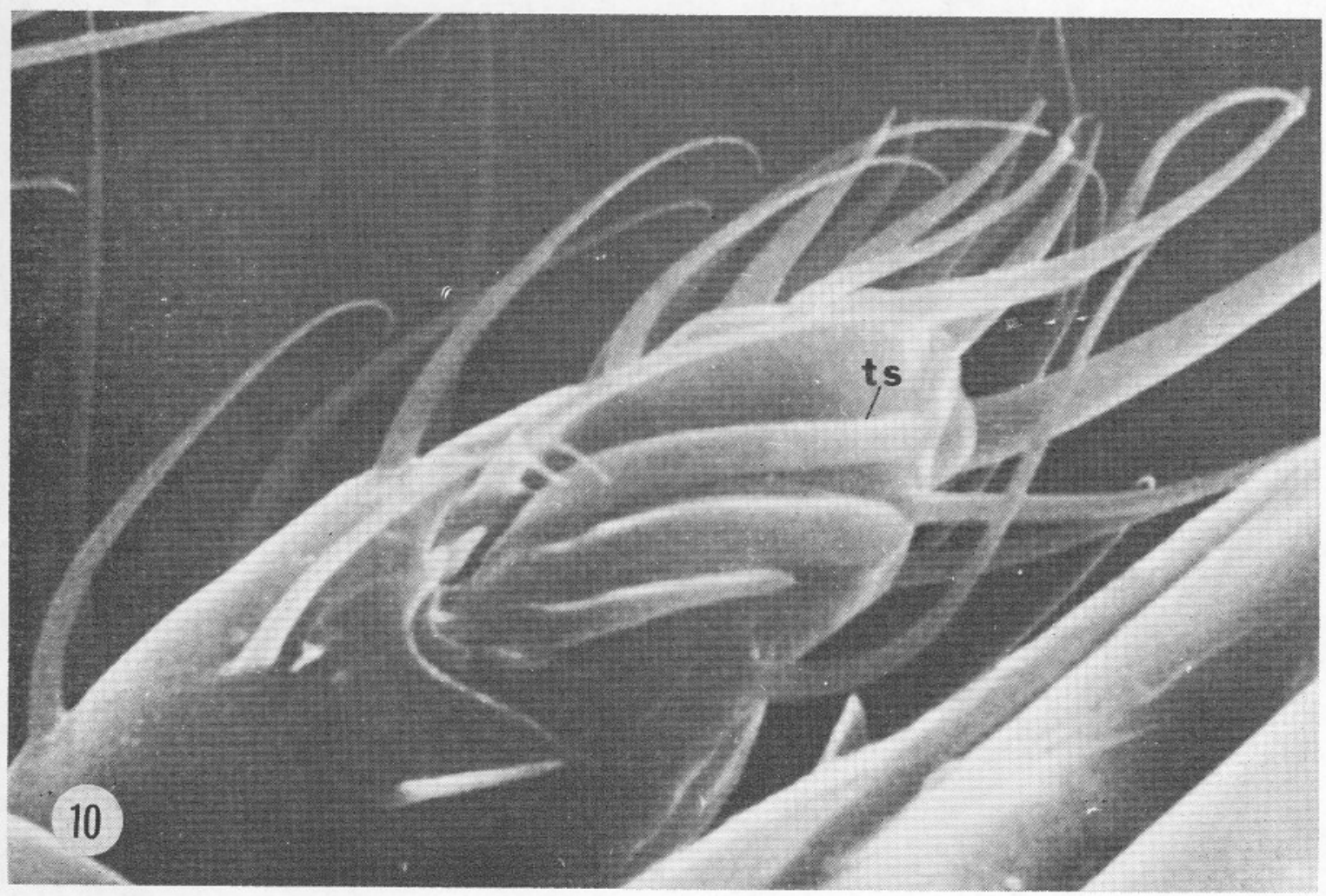

FIG. 10.- Scanning electron micrograph of the palpal tarsus of an adult female mite. Note the absence of blunt pegs or papillae. The tined setae (palpal apotele) (ts) is identified. Material fixed in alcohol. $\times 2500$.

to any particular setae. Although the foregoing speculation seems reasonable, further investigation is necessary to fully elucidate the setal types.

These findings on the tarsal setae support the preliminary results reported by Slifer (1970) and Jalil and Rodriguez (1970). The latter painted the setae at the tip of the 1st tarsus and demonstrated interference with olfactory perception. They distinguished between "apical" and "lateral" setae and concluded that the odor perception was due to the long apical setae and not to the lateral setae. The apical group obviously included both the blunt pegs and the long pointed setae and not just a single type of sensillum. On the basis of morphology, most likely the covering of the blunt pegs was the important factor in the interruption of olfactory perception. To paint only those sensilla would be impossible, because of the small size and closeness of other setae. Even to selectively paint only apical or lateral setae is a very difficult task.

Particular note should be made of the change in setal number and arrangement after the larval stage. The larval pattern changes to the "adult" pattern during the 1st molt, and then it changes only slightly by addition of 1 more peg during the next 2 molts. The larval stage is believed to be nonfeeding, and therefore the establishment of the adult pattern of setae on tarsi I coincides with the initiation of the feeding stages.

The lack of success in finding blunt pegs on the palps correlates with the evidence that the palps are not involved in olfactory perception. The behavioral evidence for contact reception by the palps (Farish and Axtell 1966) suggests that more investigation is needed. Some of the setae should be innervated and have some type of terminal or subterminal pore, but we failed to obtain any such evidence. The lack of innervation of the palpal apotele confirms the generally accepted view that this structure is nonsensory and is derived from an ancestral claw.

\section{REFERENCES CITED}

Anderson, J. R., and J. H. Poorbaugh. 1964. Observations on the ethology and ecology of various Diptera associated with northern California poultry ranches. J. Med. Entomol. 1(2) : 131-47.

Axtell, R. C. 1968. Integrated house fly control: Populations of fly larvae and predaceous mites, Macrocheles muscaedomesticae, in poultry manure after larvicide treatment. J. Econ. Entomol. 61: 245-9.

1969. Macrochelidae (Acarina: Mesostigmata) as biological control agents for synanthropic Diptera. Proc. 2nd Int. Congr. Acarol. (1967), p. 401-16.

1970 a. Integrated fly control program for cagedpoultry houses. J. Econ. Entomol. 63: 400-5.

$1970 \mathrm{~b}$. Fly control in caged-poultry houses: Comparison of larviciding and integrated control programs. Ibid. $63: 1734-7$.

Axtell, R. C., R. Foelix, L. B. Coons, and M. A. Roshdy. 1973. Sensory receptors in ticks and mites. Proc. 3rd Int. Congr. Acarol. (1971). (In press.)

Bruce, W. A. 1971. Perception of infrared radiation by the spiny rat mite Laelaps echidnina (Acari: Laelapidae). Ann. Entomol. Soc. Am, 64: 925-31. 
Camin, J. H., G. M. Clark, and F. G. Bourdeau. 1958. The palpal "tined seta" in the Mesostigmata, a homologue of the palpal claw in the Onychopalpida (Acarina). Proc. 10th Int. Congr. Entomol. 1: 903-8.

Coons, L. B., and R. C. Axtell. 1971a. Ultrastructure of the excretory tubes of the mite Macrocheles muscaedomesticae (Mesostigmata, Macrochelidae) with notes on altered mitochondria. J. Morphol. $133(3): 319-38$.

1971b. Cellular organization in the synganglion of the mite Macrocheles muscaedomesticae (Acarina: Macrochelidae): an electron microscopic study. Z. Zellforsch. Mikrosk. Anat. 119: 309-20.

Farish, D. J., and R. C. Axtell. 1966. Sensory functions of the palps and first tarsi of Macrocheles muscaedomesticae (Acarina: Macrochelidae), a predator of the house fly. Ann. Entomol. Soc. Am. 59: $165-70$.

1971. Phoresy redefined and examined in Macrocheles muscaedomesticae (Acarina: Macrochelidae). Acarologia 13(1): 16-29.

Filipponi, A. 1964. The feasibility of mass producing macrochelid mites for field trials against house flies. Bull. W.H.O. 31: 499-501.

Foelix, R. F., and R. C. Axtell. 1971. Fine structure of tarsal sensilla in the tick Amblyomma americanum (L.). Z. Zellforsch. Mikrosk. Anta. 114: 22-37.

1972. Ultrastructure of Haller's organ in the tick Amblyomma americanum (L.). Ibid. 124: 275-92.

Jalil, M., and J. G. Rodriguez. 1970. Behavioral studies of Macrocheles muscaedomesticae (Acarina:
Macrochelidae) with emphasis in its attraction to the house fly. Ann. Entomol. Soc. Am. 63: 738-44.

Luft, J. H. 1961. Improvements in epoxy resin embedding methods. J. Biophys. Biochem. Cytol. 9: $409-14$.

Osorno-Mesa, E., E. DeOsorno, and A. M. Alarcon. 1966. A technique for permanent mounts of Phlebotomus applicable to other small insects. J. Med. Entomol. 3: 124-6.

Peck, J. H., and J. R. Anderson. 1969a. Arthropod predators of immature diptera developing in poultry droppings in northern California. Part I. Determination, seasonal abundance and natural cohabitation with prey. Ibid. 6(2): 163-7.

1969b. Arthropod predators of immature diptera developing in poultry droppings in northern California. Part II. Laboratory studies on feeding behavior and predation potential of selected species. Ibid. 6(2) : $168-71$.

1970. Influence of poultry-manure-removal schedules on various Diptera larvae and selected arthropod predators. J. Econ. Entomol, 63: 82-90.

Slifer, E. H. 1970. The structure of arthropod chemoreceptors, Annu, Rev, Entomol. 15: 121-42.

Venable, J. H., and R. Coggeshall. 1965. A simplified lead citrate stain for use in electron microscopy. J. Cell Biol, 407-8.

Wade, C. F., and J. G. Rodriguez. 1961. The nutrition of Macrocheles muscaedomesticae (Acarina: Macrochelidae) in relation to its predatory action on the house fly egg. Ann. Entomol. Soc. Am. 54: 782-8. 